\title{
Evaluación de dos experiencias de enseñanza con el uso de infográficos como estrategia de aprendizaje
}

\author{
(Evaluation of Two Teaching Experiences Using Infographics \\ as a Learning Strategy)
}

\begin{abstract}
SElenNe Ríos Higuera Escuela Normal Superior de Hermosillo, Sonora, México
Mirián Adriana Noriega JACOB iD, Escuela Normal Superior de Hermosillo, Sonora, México

Rosa AsCEnCión EsPinoza CiD iD, Escuela Normal Superior de Hermosillo, Sonora, México
\end{abstract}

\author{
Volumen 4, Número 2 \\ Julio - diciembre de 2019 \\ p. $25-47$
}

Este número se publicó el 23 de agosto de 2019

Artículo recibido: 4 de septiembre de 2018

Artículo aceptado para publicación: 2 de julio de 2019

ISSN: 2448-5942, doi: https://doi.org/10.36799/el.v4i2.93

Citar este artículo como:

Ríos Higuera, S., Noriega Jacob, M. A., y Espinoza Cid, R. A. (2019). Evaluación de dos experiencias de enseñanza con el uso de infográficos como estrategia de aprendizaje. Estudios גambda. Teoría y práctica de la didáctica en Lengua y Literatura. , 4(2), 25-47. https://doi.org/10.36799/el.v4i2.93

Derechos de autor: El autor o autores conservan en todo momento sus derechos morales y patrimoniales sobre la obra; la obra no se puede alterar, transformar o ampliar; siempre debe reconocerse la autoría del documento referido. Ninguna de las modalidades de los documentos publicados en Estudios $\lambda a m b d a$. Teoría y práctica de la didáctica en lengua y literatura tienen fines comerciales de naturaleza alguna.

Los contenidos de este artículo están bajo una licencia de Creative Commons Atribución No Comercial- Sin Derivadas 4.0 Internacional 


\title{
Evaluación de dos experiencias de enseñanza con el uso de infográficos como estrategia de aprendizaje
}

\author{
Evaluation of Two Teaching Experiences Using Infographics \\ as a Learning Strategy
}

\author{
SELENNE RÍOS HigUERA ${ }^{1}$ \\ Mirí́N ADRIANA NORIEGA JACOB ${ }^{2}$ \\ ROSA ASCENCIÓN ESPINOZA CID ${ }^{3}$
}

\section{RESUMEN}

En el presente trabajo se comparten dos experiencias de enseñanza con el uso de infográficos como estrategia de aprendizaje, ambas experiencias llevadas a cabo por una maestra con un grupo de alumnos durante cuarto y quinto semestres de licenciatura en una escuela normal superior. En cada semestre, se solicitó a los normalistas realizar infográficos donde incluyeran ideas principales de temas académicos. Se hizo un análisis tanto de los infográficos producidos como de las experiencias de enseñanza. Para analizar los infográficos, se diseñó una rúbrica que consideraba dos rubros, uno de forma y otro de contenido; a su vez, cada rubro se componía de diferentes aspectos para evaluar los infográficos en escala Likert. En cuanto a la experiencia, se hizo un análisis en función de las valoraciones obtenidas de los infográficos y de las fases desarrolladas para su elaboración. Los resultados sugieren que hubo una mejora general en los infográficos producidos en quinto semestre en comparación con los producidos en cuarto; sin embargo, se identificaron áreas de oportunidad en el proceso de producción de los mismos, específicamente en las fases 1 y 2 . Como conclusión, se considera que la infografía puede ser un recurso adecuado para lograr que los estudiantes capten las ideas principales y para promover la difusión de información con bases teóricas. Por tanto, el artículo concluye con la presentación de una propuesta para su promoción en el ámbito académico.

PALABRAS CLAVE: estrategia, enseñanza, didáctica, infográficos.

\section{ABSTRACT}

This paper presents two teaching experiences with the use of infographics as a learning strategy, both experiences carried out by a teacher with a group of students during fourth and fifth semester of the undergraduate program of an escuela normal superior. In each semester, the students were required to produce infographics that included the main ideas of academic themes. An analysis of the infographics as well as the teaching experiences was conducted. To analyze the infographics, a rubric was designed; it considered two main items, one related to form and the other one related to content;

\footnotetext{
${ }^{1}$ Selenne Ríos Higuera. Es profesora en la Escuela Normal Superior de Hermosillo desde el 2010, desempeñándose como formadora de docentes y, desde enero del 2017, como coordinadora del área de Investigación, Diseño y Desarrollo Académico. Es Maestra en Educación Especial por la Escuela Normal Superior de Hermosillo. Las líneas de investigación en las que trabaja son la comprensión lectora y la enseñanza del inglés como segunda lengua o como lengua extranjera. ORCID: http://orcid.org/0000-0002-6379-8334 Correo electrónico: selennerioshiguera@gmail.com, ensh_srios@ifodes.edu.mx.

2 Mirián Adriana Noriega Jacob es Doctora en Humanidades por la Universidad de Sonora; actualmente es investigadora en CRESON. Sus líneas de investigación son: procesos de enseñanza y aprendizaje de la lengua, didáctica de la lengua, comprensión de textos. Su publicación reciente es: Noriega Jacob, Mirián Adriana. “¿Para qué enseñar español en educación primaria?”. Estudios Lambda. Teoría y práctica de la didáctica de la lengua y literatura, 2 (2017): 72-93. ORCID: https://orcid.org/0000-0002-2968-

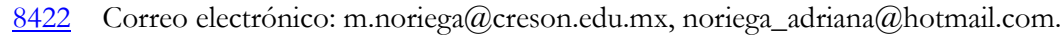

${ }^{3}$ Rosa Ascención Espinoza Cid. Es profesora en la Escuela Normal Superior de Hermosillo desde el 2012, desempeñándose como formadora de docentes y, desde enero del 2017, como coordinadora del área de Servicio Social. Es Maestra en Educación Especial por la Escuela Normal Superior de Hermosillo. Las líneas de investigación en las que trabaja son la comprensión lectora y la enseñanza del inglés como segunda lengua o como lengua extranjera. ORCID: https://orcid.org/0000-0003-1327-5364. Correo electrónico: rosa_espinoza@hotmail.com, ensh_respinoza@ifodes.edu.mx.
}

Artículo recibido: 4 de septiembre de 2018

Artículo aceptado para publicación: 2 de julio de 2019 
each item consisted of different aspects to evaluate the infographics in Likert scale. Regarding the experience, an analysis was conducted in relation to the scores of the infographics and the phases developed for their production. The results suggest that there was a general improvement in the infographics produced in fifth semester in comparison to the ones produced in fourth semester; however, some weaknesses were identified in the production process, specifically in phases 1 and 2. As a conclusion, it is considered that infographics may be an appropriate resource for students to identify main ideas and to promote the information diffusion with theoretical bases. Therefore, this article concludes with the presentation of a proposal to promote such resource in the academic field.

KEY WORDS: strategy, teaching, didactic, infographics.

\section{INTRODUCCIÓN}

La lengua evoluciona paulatinamente. Este proceso incluye cambios lingüísticos y extralingüísticos. Particularmente este último se evidencia en la creación de diferentes tipos de textos, uso de nuevos formatos e innovación de recursos gráfico-textuales que se emplean para compartir alguna idea. La evolución de la lengua puede suscitarse en diferentes contextos y gradualmente se incorpora a algún ámbito en particular, tal es el caso de la creación y el uso de infográficos. Las infografías surgen en el contexto periodístico (Guzmán, Lima y Ferreira, 2015, 962) con el fin de presentar hechos de manera puntual y atractiva a los lectores. Sin embargo, es importante que en el ámbito educativo los docentes hagan uso de las herramientas que se ajusten al contexto en el que se desenvuelven sus alumnos para mejorar su aprendizaje y captar su interés. De esta forma, la infografía es un recurso que se puede utilizar para favorecer el proceso de enseñanza-aprendizaje, ya que, además de constituir un medio importante para transmitir información en la actualidad, es un recurso que puede contribuir a la alfabetización visual de los estudiantes, lo cual es esencial para los educadores (Alyahya, 2019, 1).

Este recurso gráfico-textual se empezó a utilizar recientemente en el ámbito educativo (García, 2014 en Guzmán, Lima y Ferreira, 2015, 964). De hecho, Ponce, Rangone y Funes (2015) reportan la experiencia del uso de infografías como estrategia en centros argentinos de formación de docentes de primaria. Por su parte, Davis y Quinn $(2013,18)$ sustentan con su estudio que la utilización de infográficos contribuye al desarrollo del conocimiento de los estudiantes, así como también al desarrollo de la comprensión lectora y la expresión escrita, a la vez que fortalece el pensamiento crítico y las habilidades de sintetización.

El presente documento aborda como tema central el uso de infografías como estrategia de aprendizaje en la formación de futuros docentes de inglés en educación secundaria y se hace un análisis tanto de los infográficos producidos como de las experiencias de enseñanza llevadas a cabo. A pesar de que los cambios en la tecnología y comunicación de alguna manera han 
promovido mayor participación en la producción y en el uso de la lengua escrita en formatos no tradicionales, en las aulas se observa el desinterés de los estudiantes por la práctica lectora de diversos tipos de texto, incluyendo los textos académicos y científicos. Sin embargo, los materiales de lectura en formatos que incluyen imágenes además de grafías, como los infográficos, suelen resultar más atractivos para los jóvenes estudiantes. La hipótesis central planteada en este artículo se sitúa en el uso de infográficos como una actividad de aprendizaje que permita al alumno no solamente apropiarse de conocimiento sino también de difundirlo por los medios que considere aptos según el contexto donde se encuentre.

\section{LA INFOGRAFÍA: UN RECURSO GRÁFICO-TEXTUAL}

Centrando la atención en la infografía, el último recurso mencionado en el párrafo anterior, es una representación visual de la información, de datos y de conocimiento (Damyanov y Tsankov, 2018, 84) que contiene un alto grado de apoyo visual y datos concretos que transmiten la información y permiten su comprensión de temas complejos de igual forma o incluso con mayor eficiencia que otros tipos de comunicación textual (Guzmán, Lima y Ferreira, 2015). De Pablos $(1998,15)$ sostiene que la infografía ha estado presente desde la época de las cavernas, aun sin ser catalogada como tal.

Según Damyanov y Tsankov $(2018,84)$, existen tres tipos principales de infográficos. El primer tipo son los denominados estáticos, los cuales son los más simples y comunes; generalmente contienen una imagen sin elementos animados. El segundo tipo son los denominados interactivos, los cuales contienen elementos animados y permiten la visualización de gran cantidad de información a primera vista. Finalmente, el tercero tipo son los llamados videoinfográficos, los cuales son una combinación de videos cortos con imágenes, ilustraciones y texto. Cabe resaltar que los infográficos contienen principalmente tres componentes: elementos visuales, elementos de contenido y conocimiento (Damyanov y Tsankov, 2018, 84-85).

De acuerdo con Guzmán, Lima y Ferreira (2015, 963), la infografía facilita la comprensión del tema adaptable al público al cual irá dirigido el mensaje. Asimismo, los autores señalan que este recurso gráfico se caracteriza por: la coherencia entre el texto y la imagen, la proporción entre imágenes y datos, la diagramación, el uso de tipografía, el fin informativo, la claridad del mensaje, la calidad en las imágenes y la estructura del contenido. Una infografía que 
pretende transmitir conocimientos científicos debe ser informativa, clara y comprensible (Valero, 2002 en Guzmán, Lima y Ferreira, 2015, 963), lo cual conlleva respetar el aspecto estético al utilizar íconos, cuidar la tipografía y cuidar aspectos lingüísticos y de redacción.

\section{LA INFOGRAFÍA COMO RECURSO DIDÁCTICO}

En el ámbito educativo, la infografía didáctica tiene como finalidad el aprendizaje del alumno según los contenidos abordados. En otras palabras, la infografía didáctica se trabaja como un producto de aprendizaje (Guzmán, Lima y Ferreira, 2015, 965). Sin embargo, lo anterior no exime de considerar y respetar las características ya planteadas como parte de las características del infográfico con fines distintos al uso didáctico.

Para comprender el concepto de infografía didáctica, es importante definir primero qué es una estrategia didáctica. Tébar $(2003,7)$ define las estrategias didácticas como procedimientos que los maestros utilizan "en forma reflexiva y flexible para promover el logro de aprendizajes significativos en los estudiantes”. Dentro de las estrategias didácticas, Tapia (1997) organiza dos categorías: las de aprendizaje y las de enseñanza. Las estrategias de enseñanza son utilizadas por el agente de enseñanza, su finalidad es promover y facilitar el aprendizaje significativo de los estudiantes. Por otro lado, las estrategias de aprendizaje, son utilizadas por los alumnos para reconocer, aprender y aplicar la información o también de contenido.

A partir de estos conceptos y considerando algunos estudios, se deduce que la infografía como recurso didáctico puede ser utilizada de ambas formas. Primeramente, su uso como estrategia de aprendizaje implica que el alumno elabore la infografía como una forma de evidenciar su comprensión sobre un tema (ver estudio de Guzmán, Lima y Ferreira, 2015). Segundo, la utilización del infográfico en el sentido de estrategia de enseñanza por parte del docente consiste en que a los alumnos se les presente la infografía con el objetivo de transmitir el conocimiento o la información (ver estudios de Minervini, 2005; Ponce, Rangone, y Funes, 2015; Reinhart, 2010; Sudakov, Bellsky, Usenyuk y Polyakova, 2016). En relación a esto último, Reinhart (2010) reflexiona sobre la infografía como recurso didáctico propicio para el aprendizaje significativo, planteando varios cuestionamientos acerca de la posibilidad de que ésta resulte contraproducente para el alumno, ya que la información se le presenta procesada, fácil y sintética. Siendo así, al alumno estaría evitando un esfuerzo cognitivo para comprender un tema, 
lo cual puede llevarnos a legitimar una "actitud facilista y cómoda de una sociedad que ya no quiere pensar" (Reinhart, 2010, 126).

Ante este posible panorama, en esta experiencia áulica se optó por la realización de infografías por parte de los estudiantes, es decir, como estrategia de aprendizaje. De esta manera, se lograría que pusieran en práctica sus habilidades de comprensión lectora, presentándoles además una "oportunidad de promover tanto habilidades de investigación como competencias digitales” (Guzmán, Lima y Ferreira, 2015, 964).

\section{INTERVENCIÓN}

En ambas experiencias áulicas participaron 19 estudiantes de una escuela normal superior de la región noroeste de México. Participaron cuatro hombres y 15 mujeres. La edad del grupo de los normalistas oscilaba entre los 20 y 24 años. La producción de los infográficos se realizó en dos momentos. En el primer momento los estudiantes se encontraban en cuarto semestre y en el segundo ellos cursaban el quinto semestre.

El proceso de elaboración de infográficos se conformó por tres fases en cada semestre. En la primera fase, se establecieron las instrucciones para la elaboración de dicho producto. Cabe señalar que los temas de las lecturas se centraron en contenidos relacionados con la asignatura "Planeación de la enseñanza y evaluación del aprendizaje” en cuarto semestre y la asignatura de "Observación y práctica docente III" en quinto semestre. Durante la segunda fase, los estudiantes realizaron los infográficos con el acompañamiento de la profesora, el cual consistió en atender dudas sobre los textos propuestos para su lectura que corresponden a la base para realizar las infografías. También se dio acompañamiento en relación al proceso de elaboración del infográfico, y se ofrecieron sugerencias a modo de correcciones a quienes lo solicitaron. La tercera fase tuvo por propósito la socialización de los infográficos, esto de manera presencial en las clases y a través de un grupo de Whatsapp en el que se encontraban todos los estudiantes participantes en esta experiencia áulica. Es importante señalar que el total de infográficos fue de nueve, cinco producidos durante el cuarto semestre y cuatro en quinto semestre.

En cuanto a la información contenida en los textos con los que trabajaron los alumnos, es necesario dar una breve y general descripción de los textos que se asignaron a los normalistas en esta experiencia áulica. Los temas de las lecturas utilizadas en cuarto semestre eran 
relacionados a tipos de reactivos para exámenes de inglés como segunda lengua o como lengua extranjera. Los textos contenían información puntual y no contenían conceptos que requirieran de un procesamiento cognitivo profundo para su comprensión, o que pudieran representar de alguna forma un desafío para los estudiantes. Aunado a esto, los estudiantes normalistas tuvieron la libertad de elegir los textos de diversas fuentes de internet, por lo que en su mayoría eran textos dirigidos a la comunidad docente en general. El lenguaje utilizado en estos textos es práctico y no teórico, y la información se presentaba de manera organizada y simplificada, haciendo poco uso de terminología especializada y con una extensión que pudiera considerarse corta. En cambio, en quinto semestre los textos eran de autores que trabajan temas, teorías y conceptos relacionados con el ámbito de la enseñanza de segundas lenguas, y contenían una cantidad de información mayor, además de términos y conceptos especializados, los cuales eran sobre dos temas: 1) la disciplina en el aula y 2) la corrección de errores al trabajar la habilidad oral en inglés. La información contenida en estos textos se caracterizaba por ser abstracta y teórica más que práctica. Cabe señalar que en este semestre a los alumnos se les asignaron los textos, por lo que no tenían la opción de escoger según sus preferencias.

El instrumento utilizado para la valoración de los infográficos producidos por los normalistas fue una rúbrica (ver Anexo) por parte del equipo de investigación. La rúbrica se conformó por dos principales rubros. El primer rubro consideraba cinco aspectos de contenido, y el segundo incluía siete aspectos de forma (véase Tabla 1). La rúbrica se creó considerando como base las características de los infográficos según Guzmán, Lima y Ferreira (2015, 963), mismas que se mencionaron en el apartado donde se discute el tema de la infografía como recurso gráfico-textual. Además, se incluyeron otros aspectos que se consideraban pertinentes para una mejor calidad de los productos y para cumplir con el principal objetivo de la actividad, el cual era plasmar en las infografías las ideas principales de los textos leídos, razón por la cual se incorporó el aspecto de contenido número 3 que se muestra en la Tabla 1. Otro de los aspectos que se consideró necesario fue el aspecto de contenido "Referencia", este con la finalidad de valorar las fuentes de consulta utilizadas por los normalistas.

Aspecto de contenido

1. Apoyo para la comprensión de texto

2. Precisión de la información

\section{Aspecto de forma}

1. Coherencia entre texto e imagen

2. Proporción imagen-dato 
3. Logro del objetivo del organizador gráfico

4. Referencia

5. Redacción y ortografía
3. Tipografía

4. Claridad de la información

5. Calidad en la imagen

6. Estructura del contenido

7. Captura de la atención

Tabla 1. Elementos utilizados en la rúbrica para el análisis de los infográficos

Para el análisis de los infográficos se utilizó como parte de la valoración una escala tipo Likert, en la que se consideró el tipo de logro como excelente, bueno, regular y malo. Esta escala de medición tenía valores cuantitativos para la ubicación de logro. En este sentido, el valor excelente equivalía a cuatro puntos, bueno a tres, regular a dos y malo a uno. Con el propósito de analizar los logros promedios de cada aspecto, se utilizó la escala de la Tabla 2.

\begin{tabular}{cc}
\hline Promedio & Equivalente \\
\hline 4.0 & Excelente \\
$3.0-3.9$ & Bueno \\
$2.0-2.9$ & Regular \\
$1-1.9$ & Malo \\
\hline
\end{tabular}

Tabla 2. Escala de equivalencia de promedios por aspecto especifico

Finalmente, la suma de los valores cuantitativos (excelente $=4$, bueno $=3$ regular $=2 \mathrm{y}$ malo $=1)$ permitió ubicar el logro de las características de contenido y de forma, así como el logro general a través de la suma de la medición de valores. Para la realización de este análisis se utilizó como herramienta la escala de la Tabla 3. Esta escala, al igual que la anterior (Tabla 2) se estableció según el criterio del equipo de investigación. Es importante señalar que ambas escalas fueron propuestas por el equipo de investigación, a fin de establecer rangos cuantitativos a aquello cualitativo analizado en la producción de los infográficos. 


\begin{tabular}{lccc}
\hline & Contenido & Forma & General \\
\hline Excelente & $17.1-20.0$ & $23.1-28.0$ & $36.1-48.0$ \\
Bueno & $14.1-17.0$ & $17.1-23.0$ & $30.1-36.0$ \\
Regular & $8.0-14.0$ & $12.1-17.0$ & $20.1-30.0$ \\
Malo & $0-7.9$ & $8.0-12.0$ & $0-20.0$ \\
\hline
\end{tabular}

Tabla 3. Escala de medición de valores

\section{RESULTADOS}

El análisis de los infográficos se presenta en dos secciones principales. En la primera sección se evalúan los infográficos realizados cuando los estudiantes cursaban el cuarto semestre. Seguidamente, se analizan aquellos producidos durante quinto semestre. Por último, se examina de manera global el conjunto total de infográficos. En la segunda sección se evalúan las experiencias de enseñanza con el uso de infográficos como estrategia de aprendizaje.

\section{Evaluación de los infográficos}

\section{1) Infográficos producidos en cuarto semestre}

Los infográficos muestran logros mayormente en el rango de regular, particularmente los aspectos de contenido. La tarea fundamental de la realización de este tipo de organizadores gráficos es el manejo del contenido, pues a través de este los normalistas organizan, procesan y utilizan la información leída del texto base. El manejo de aspectos de forma es relevante pero no tanto como la de contenido. Sin embargo, los infográficos que los estudiantes realizaron en cuarto semestre evidencian un mejor logro en elementos de forma que de contenido (véanse Tabla 4 y Tabla 5).

\begin{tabular}{lccccc}
\hline & Infográfico 1 & Infográfico 2 & Infográfico 3 & Infográfico 4 & Infográfico 5 \\
\hline Logro de contenido & 11 & 17 & 13 & 17 & 12 \\
Logro de forma & 18 & 18 & 17 & 21 & 16 \\
Logro general & 29 & 35 & 30 & 38 & 28
\end{tabular}


Tabla 4. Puntaje de logro de los infográficos producidos por normalistas en cuarto semestre

\begin{tabular}{lccc}
\hline & Excelente & Bueno & Regular \\
\hline Logro de contenido & 0 & 2 & 3 \\
Logro de forma & 0 & 4 & 1 \\
Logro general & 1 & 1 & 3 \\
\hline Tabla 5. Logros de infográficos de normalistas en cuarto semestre
\end{tabular}

Los organizadores gráficos en términos de contenido evidencian mejor manejo de redacción y ortografía, así como la precisión de la información presentada en ellos. Sin embargo, los infográficos no logran suficientemente el cumplimiento del objetivo, tampoco ofrecen el apoyo necesario para la comprender el texto base ni hacen uso de referencia al texto utilizado. Respecto a los elementos de forma que fueron analizados, se observa que tienen buen manejo de estructura de contenido y claridad visual de la información presentada pero poca coherencia entre texto e imagen, proporción de imagen - dato, captura de atención y el uso de tipografía no facilita la lectura (véase Tabla 6).

\begin{tabular}{|c|c|c|c|c|c|}
\hline $\begin{array}{l}\text { Aspectos de } \\
\text { contenido }\end{array}$ & Promedio & Equivalencia & $\begin{array}{l}\text { Aspectos de } \\
\text { forma }\end{array}$ & Promedio & Equivalencia \\
\hline $\begin{array}{l}\text { Apoyo para la } \\
\text { comprensión de texto }\end{array}$ & 2.4 & regular & $\begin{array}{r}\text { Coherencia entre } \\
\text { texto e imagen }\end{array}$ & 2.2 & regular \\
\hline $\begin{array}{r}\text { Precisión de la } \\
\text { información }\end{array}$ & 3 & bueno & $\begin{array}{l}\text { Proporción } \\
\text { imagen-dato }\end{array}$ & 2 & regular \\
\hline $\begin{array}{l}\text { Logro del objetivo del } \\
\text { organizador gráfico }\end{array}$ & 2.8 & regular & Tipografía & 2.2 & regular \\
\hline Referencia & 2.2 & regular & $\begin{array}{r}\text { Claridad de la } \\
\text { información }\end{array}$ & 3.4 & bueno \\
\hline \multirow[t]{2}{*}{ Redacción y ortografía } & 3.6 & bueno & $\begin{array}{r}\text { Calidad en la } \\
\text { imagen }\end{array}$ & 3 & bueno \\
\hline & & & $\begin{array}{r}\text { Estructura del } \\
\text { contenido }\end{array}$ & 3.4 & bueno \\
\hline
\end{tabular}




\begin{tabular}{c|cccc}
\cline { 2 - 3 } & $\begin{array}{c}\text { Captura de la } \\
\text { atención }\end{array}$ & 2.4 & regular \\
\hline
\end{tabular}

Tabla 6. Logros promedio de contenido y forma de infográficos realizados por normalistas en cuarto semestre

En síntesis, los infográficos realizados por los normalistas en cuarto semestre muestran logros relativamente buenos, pero con mayores deficiencias en cuestiones de contenido que de forma (véase Tabla 7).

\begin{tabular}{lcc}
\hline & Promedio de puntaje & Equivalencia \\
\hline Logro de contenido & 14 & Regular \\
Logro de forma & 18 & Bueno \\
Logro general & 32 & Bueno
\end{tabular}

Tabla 7. Logro promedio de puntaje de los infográficos de normalistas en cuarto semestre

\section{2) Infográficos producidos en quinto semestre}

En los infográficos realizados en quinto semestre se visualiza un mejor desempeño en los aspectos de forma que en los de contenido (véase Tabla 8). Por otro lado, los resultados muestran una mejora general tanto en contenido como en forma; contrastando con los resultados obtenidos en cuarto semestre, los ubicados realizados en quinto semestre se ubican principalmente en las categorías de “excelente” y "bueno" (véanse Tabla 5 y Tabla 9).

\begin{tabular}{lcccc}
\hline & Infográfico 6 & Infográfico 7 & Infográfico 8 & Infográfico 9 \\
\hline Logro de contenido & 8 & 18 & 18 & 13 \\
Logro de forma & 19 & 26 & 26 & 23 \\
Logro general & 27 & 44 & 44 & 36 \\
\hline
\end{tabular}

Tabla 8. Puntaje de logro de los infográficos producidos por normalistas en quinto semestre

\begin{tabular}{lccc}
\hline & Excelente & Bueno & Regular \\
\hline Logro de contenido & 2 & 0 & 2 \\
Logro de forma & 2 & 2 & 0 \\
Logro general & 2 & 1 & 1 \\
\hline
\end{tabular}

Tabla 9. Logros de infográficos de normalistas en quinto semestre 
Por otra parte, en cuanto a contenido, los resultados muestran que en quinto semestre el aspecto de logro del objetivo del organizador gráfico mejoró (véase Tabla 10) en comparación con el cuarto semestre, pasando de la categoría "regular" a "bueno". Sin embargo, también se observa un decremento en el aspecto de redacción y ortografía en comparación con los resultados del cuarto semestre. En relación a los aspectos de forma, los resultados muestran un desempeño bueno los aspectos de tipografía y captura de la atención, los cuales son aspectos importantes para la visualización de información en este tipo de recursos; sin embargo, los aspectos de coherencia entre texto e imagen y claridad en la información son los que reflejan un menor desempeño (véase Tabla 6). A pesar de esto, es importante señalar que el aspecto de coherencia entre texto e imagen mejoró, pasando de "regular" en cuarto semestre a "bueno" en quinto. No obstante, se observa un decremento en el aspecto de claridad de la información en el quinto en relación al cuarto semestre (véanse Tabla 6 y Tabla 10).

\begin{tabular}{|c|c|c|c|c|c|}
\hline $\begin{array}{l}\text { Aspectos de } \\
\text { contenido }\end{array}$ & Promedio & Equivalencia & $\begin{array}{l}\text { Aspectos de } \\
\text { forma }\end{array}$ & Promedio & Equivalencia \\
\hline $\begin{array}{r}\text { Apoyo para la } \\
\text { comprensión de texto }\end{array}$ & 3 & bueno & $\begin{array}{r}\text { Coherencia entre } \\
\text { texto e imagen }\end{array}$ & 3 & bueno \\
\hline $\begin{array}{r}\text { Precisión de la } \\
\text { información }\end{array}$ & 2.7 & regular & $\begin{array}{r}\text { Proporción } \\
\text { imagen-dato }\end{array}$ & 3.2 & bueno \\
\hline $\begin{array}{l}\text { Logro del objetivo del } \\
\text { organizador gráfico }\end{array}$ & 3.2 & bueno & Tipografía & 3.7 & bueno \\
\hline Referencia & 2.7 & regular & $\begin{array}{r}\text { Claridad de la } \\
\text { información }\end{array}$ & 3 & bueno \\
\hline \multirow[t]{3}{*}{ Redacción y ortografía } & 2.5 & regular & $\begin{array}{r}\text { Calidad en la } \\
\text { imagen }\end{array}$ & 3.5 & bueno \\
\hline & & & $\begin{array}{r}\text { Estructura del } \\
\text { contenido }\end{array}$ & 3.2 & bueno \\
\hline & & & $\begin{array}{r}\text { Captura de la } \\
\text { atención }\end{array}$ & 3.7 & bueno \\
\hline
\end{tabular}

Tabla 10. Logros promedio de contenido y forma de infográficos realizados por normalistas en quinto semestre 
Los resultados obtenidos de los infográficos realizados por normalistas en quinto semestre muestran que, al igual que en cuarto semestre, hubo mejor desempeño en los aspectos de forma que de contenido (véanse Tabla 7 y Tabla 11). A pesar de ello, se observa una mejora general que los ubica en la categoría de “excelente” (véase Tabla 11).

\begin{tabular}{lcc}
\hline & Promedio de puntaje & Equivalencia \\
\hline Logro de contenido & 14.2 & Bueno \\
Logro de forma & 23.5 & Excelente \\
Logro general & 37.7 & Excelente \\
\hline
\end{tabular}

Tabla 11. Logro promedio de puntaje de los infográficos de normalistas en quinto semestre

\section{3) Resultados globales}

Por último y de manera global, los resultados obtenidos de los infográficos realizados tanto en cuarto como en quinto semestre muestran que fueron producciones buenas, con mayores puntajes de logro en forma que en contenido (véase Tabla 12).

\begin{tabular}{lcc}
\hline & Promedio de puntaje & Equivalencia \\
\hline Logro de contenido & 14.1 & Bueno \\
Logro de forma & 20.7 & Bueno \\
Logro general & 34.8 & Bueno \\
\hline
\end{tabular}

\section{EVALUACIÓN DE LAS EXPERIENCIAS DE PRODUCCIÓN DE INFOGRÁFICOS}

Aun cuando se puede considerar que los infográficos producidos por los alumnos fueron, en términos generales y a partir de la valoración por medio de la rúbrica, buenos, es necesario realizar un análisis de las dos experiencias de enseñanza, de tal forma que esto permita reflexionar sobre la práctica para proponer mejoras. Cabe mencionar que se evaluó el proceso de estas experiencias de enseñanza a partir de tres puntos: 1) la premisa de la que se partió para asignar a los estudiantes la tarea de elaborar infográficos, 2) la edición de los infográficos y 3) la difusión de los mismos. 
Primeramente, la premisa de la cual se partió para asignar a los estudiantes la consigna de elaborar infográficos fue que ellos ya habían tenido contacto con este tipo de material debido al contexto en el que se desenvuelven. Esto se corroboró al cuestionarles sobre su conocimiento acerca de lo que son los infográficos, a lo que ellos respondieron que sí los conocían y los habían visto. Partiendo de esta afirmación, se procedió a asignar la tarea. Debido a ello, no se proporcionó a los estudiantes información sobre los tipos de infográficos (estáticos, interactivos y videoinfográficos); además, tampoco se solicitó a los alumnos que buscaran información al respecto, de tal forma que fueran ellos quienes decidieron qué tipo de infografía realizar. Si bien es cierto que el conocimiento sobre y el acercamiento a este tipo de material no es ajeno a los alumnos, esto no necesariamente garantiza que ellos conozcan de manera consciente las características que deben tener los infográficos para que cumplan su propósito. Además de que no se dio a los alumnos información explícita sobre qué son los infográficos y cómo elaborarlos, tampoco se les indicó qué software se puede utilizar para ello. Tampoco se presentaron a los estudiantes ejemplos de infográficos para analizarlos y partir de ese análisis para elaborar los propios. A pesar de esto, los alumnos no mostraron dificultad para encontrar herramientas con las cuales elaborar la tarea, utilizando principalmente PowerPoint, Piktochart y Canva.

El segundo punto importante de analizar es el proceso de edición. Durante la elaboración de los infográficos, se estuvieron resolviendo dudas acerca del contenido de las lecturas. Los alumnos no externaron dudas acerca del proceso de elaboración de la infografía. Si bien es cierto esto no justifica la omisión de esta información, se partió del supuesto de que ellos ya sabían cómo elaborar los infográficos o estaban indagando al respecto durante el proceso. Sin embargo, a partir de la evaluación de los productos se concluye que ambos supuestos eran erróneos. Por tanto, se pudo haber implementado el proceso que se sigue para la elaboración de ensayos (Figura 1) para guiar a los alumnos hacia la elaboración de un infográfico con mejores características.

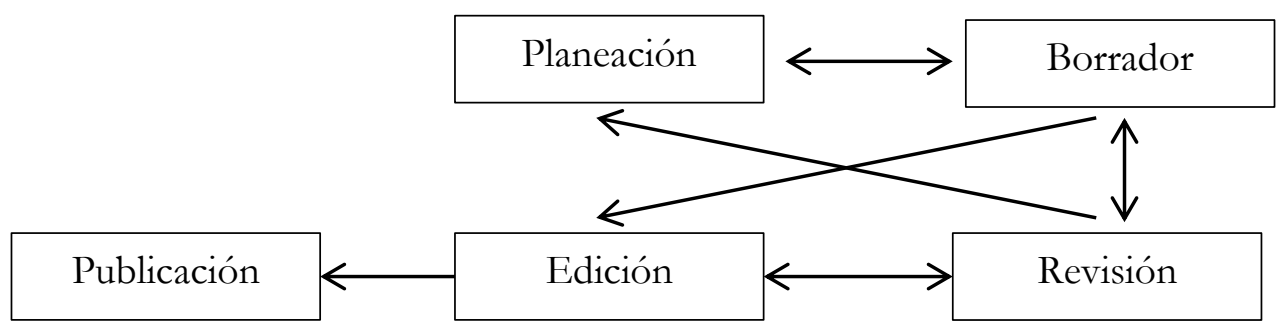

Figura 1. Proceso de escritura. Elaboración propia a partir de Oshima y Hogue (1997) 
$\mathrm{Al}$ adaptar este proceso de escritura para la elaboración de infográficos, se puede dar al alumno la oportunidad de analizar, revisar y retroalimentar el producto al menos una vez antes de entregarlo en su versión final. Dicha revisión debería incluir no únicamente el análisis del contenido a partir de la información que se ha asignado, sino también un análisis relativo a las características de infográfico.

Por último, conviene analizar la fase 3, la cual consistió en la difusión de las infografías. En la actualidad, la difusión de la información tiene un papel fundamental, es por eso que en esta fase se dieron a conocer los infográficos por medio del grupo de Whatsapp de los sujetos, grupo que se creó con la finalidad de compartir información académica. Sin embargo, se considera que el impacto no fue significativo puesto que no se dieron a conocer a la comunidad escolar, en especial a docentes, quienes reiteradamente han expuesto su interés en lo concerniente a la elaboración de ítems para el diseño de sus exámenes, el cual era uno de los temas que presentaban los infográficos.

\section{DISCUSIÓN}

Al analizar los infográficos de manera global considerando contenido y forma, los resultados muestran mejoras en los infográficos producidos en quinto semestre en relación a los producidos en cuarto, tanto en aspectos de contenido como en aspectos de forma. En cuanto a los aspectos de contenido, se observan mejores resultados en apoyo para la comprensión del texto (las imágenes y textos presentados permiten mejorar el entendimiento de la información.), logro del objetivo del organizador gráfico (explica de manera concisa las ideas principales; explica de manera concisa conceptos clave.) y referencia (todos los elementos de la referencia están en estilo APA 6ta edición, como se les solicitó a los estudiantes). Los dos primeros aspectos requieren de un procesamiento de la información leída para su posterior comprensión, por lo que los resultados sugieren que los estudiantes normalistas mejoraron su comprensión lectora y su capacidad de plasmar las ideas de manera clara para que otras personas tengan acceso a la información de una manera concisa.

Por otro lado, los aspectos de forma en los que se observaron mejoras fueron coherencia entre texto e imagen (las imágenes y el texto corresponden entre sî), proporción imagen-dato (la cantidad de información visual es proporcional a la cantidad de la información escrita), tipografía (utiliza tamaño y tipos de letra que facilitan la lectura a lo largo del infográfico), y calidad en la 
imagen (la calidad de los gráficos e imágenes utilizados permite ampliar y reducir la imagen sin ver afectado la resolución de imagen). A partir de estos datos, se llega a la conclusión de que los estudiantes produjeron infográficos más apegados a las características que este tipo de recurso debe poseer, por ejemplo, la coherencia entre el texto y la imagen, la proporción entre datos e imágenes, la tipografía, el fin informativo, la claridad del mensaje, la calidad en las imágenes utilizadas, la estructura del contenido (Valero, 2002 en Guzmán, Lima y Ferreira, 2015, 963).

Sin embargo, a pesar de que de manera general hubo mejora en los infográficos elaborados en el quinto semestre en comparación con los elaborados en cuarto semestre, existen ciertos aspectos en los que se observa un retroceso en los aspectos de "precisión de la información", "redacción y ortografía” y "estructura del contenido" (los dos primeros siendo aspectos de contenido, y el tercero perteneciente a los aspectos de forma). Lo anterior posiblemente se debió al tipo de información contenida en los textos en quinto semestre, los cuales eran textos especializados. Por último, los textos para realizar los infográficos del tema asignado en cuarto semestre estaban dirigidos a la comunidad docente en general, por lo que el lenguaje utilizado era práctico, y la información se presentaba de manera organizada y simplificada. Por ende, esto pudo facilitar a los estudiantes la estructuración del contenido de manera organizada y en una secuencia lógica, lo cual no se observa en quinto semestre y, por ende, se vio afectado el desempeño en el aspecto de "estructura del contenido". Cabe señalar que los posibles lectores de estos recursos gráficos fueron los mismos compañeros de generación con quienes socializaron las producciones de infográficos.

Por otra parte, es importante también discutir los aspectos en los que se observó mejor desempeño en cuarto semestre con relación al quinto. Dichos aspectos fueron "precisión de la información" (la infografía contiene solamente elementos textuales y visuales concretos y esenciales para la comprensión del contenido) y "redacción y ortografía" (no hay errores de redacción ni faltas de ortografía), los cuales pertenecen a la categoría de contenido; y "claridad de la información" (la información se muestra de manera clara, sin prestarse a interpretaciones equivocadas; utiliza lenguaje conciso) y "estructura del contenido" (la información se presenta de manera organizada en una secuencia lógica que facilita la lectura, haciendo uso de subtítulos y tipografía que permiten identificar la estructura global del infográfico), los cuales son aspectos de forma. Como ya se mencionó anteriormente, el tipo de texto utilizado en cuarto semestre parece haber llevado a tales resultados. 
A manera de reflexión, se considera que la experiencia de haber realizado infográficos en cuarto semestre pudo haber favorecido positivamente a los estudiantes al elaborarlos en el quinto semestre, logrando así un mejor desempeño general en la producción de los infográficos; esto a partir del proceso reflexivo generado por los normalistas en la elaboración y socialización de los infográficos. Resulta interesante que los aspectos donde se observa un mejor desempeño fueron "tipografía" y "captura de la atención", los cuales pertenecen a los aspectos de forma, lo que se puede interpretar como incremento, por parte de los estudiantes, de conciencia sobre el diseño de infográficos, pues incluso el aspecto de "proporción imagen-dato" (también aspecto de forma) mejoró significativamente. Otro aspecto que resalta por su mejora es el de "logro del objetivo del organizador gráfico", el cual pertenece a los aspectos de contenido, pues éste tiene relación directa con el principal objetivo de la clase, el cual era plasmar las ideas principales en un infográfico. En cuarto semestre el promedio en este aspecto fue de 2.8 y en quinto de 3.2, pasando de la categoría "regular" a "bueno", lo cual implica que en los infográficos los alumnos explicaron de manera concisa las ideas principales y algunos conceptos clave. A partir de esto, se interpreta que los alumnos mejoraron de un semestre a otro su comprensión lectora en el nivel inferencial, ya que pudieron inferir las ideas principales del texto. Sin embargo, como ya se señaló, los resultados sugieren que el tipo de textos utilizados en cuarto semestre favoreció en el desempeño en aspectos relacionados a la estructuración de las ideas y a la redacción.

Los resultados muestran una mejora general en la producción de infográficos del quinto semestre en comparación con los del cuarto. El aspecto de contenido "logro del objetivo del organizador gráfico" y el aspecto de forma "estructura de contenido", que a nuestra consideración reflejan en mayor medida la comprensión de un texto, sugieren que si bien hubo mejora en quinto semestre respecto del cuarto en cuanto al logro del objetivo, es decir, en explicar de manera concisa las ideas principales y los conceptos clave, todavía se tiene que trabajar la estructura del contenido, pues este aspecto es el que refleja la capacidad de los estudiantes para organizar la información en una secuencia lógica en un nivel de comprensión lectora literal, es decir, en un nivel de comprensión en el que el alumno es capaz de reconocer lo que explícitamente se dice en el texto (Catalá, Catalá, Molina y Monclús, 2001). Lo anterior implica que en primera instancia ellos comprendan el texto a profundidad antes de plasmarlo de manera clara para otros. 
A manera de conclusión y partiendo de los resultados de ambas experiencias, se considera que la infografía puede ser un recurso adecuado para lograr que los estudiantes capten las ideas principales de un texto. Además, los alumnos deben procesar la información tanto a nivel literal como inferencial, este último si se les solicita identificar ideas principales, pues la comprensión en un nivel inferencial demanda que el lector infiera información que no se explicita en el texto, tales como las ideas principales (Catalá, Catalá, Molina y Monclús, 2001). Por otra parte, este tipo de experiencia es útil para promover en los estudiantes la difusión de información con bases teóricas confiables, como fue el caso de los infográficos producidos en quinto semestre, en el cual se partió de autores de libros relacionados al ámbito de la enseñanza de segundas lenguas escritos por autores expertos y reconocidos en dicho ámbito. La experiencia planteada en este documento es un acercamiento al uso del infográfico con un grupo de futuros profesores; considerando esto se sugiere explorar desde la perspectiva de los estudiantes normalistas la experiencia y los aportes que tiene en su formación el producir infográficos como recursos didácticos, de tal forma que se analice el impacto que dicho recurso tiene en los futuros profesores y se puedan identificar áreas de mejora para que los actuales medios de comunicación, y no solamente los infográficos, sean aliados en el proceso formativo de los estudiantes, tal y como lo proponen Cassany, Luna y Sanz (2000). Por último, se presenta una propuesta para el trabajo con infográficos como estrategia de aprendizaje. Para ello, se sugiere una serie de recomendaciones para su implementación en el aula, la cual es:

\section{Fase 1: Presentación de infográficos y análisis de sus características}

1. Presentar a los estudiantes los tres tipos de infográficos que señalan Damyanov y Tsankov (2018, 84): estáticos, interactivos y videoinfográficos.

2. Analizar las características con las que las infografías deben cumplir, por ejemplo, las sugeridas por Guzmán, Lima y Ferreira (2015, 963).

\section{Fase 2: Instrucciones para el diseño de los infográficos}

1. Dar la opción de que los alumnos decidan qué tipo de infografía diseñar. Se sugiere procurar que haya diversidad en los tipos de infográficos que los alumnos deseen diseñar, o permitir que diseñen al menos dos tipos diferentes.

2. Presentar una lista de los programas o herramientas que se pueden utilizar para el diseño de las infografías. 
3. Presentar una rúbrica para la valoración de los productos en función de las características discutidas en la fase 1.

\section{Fase 3: Elaboración de los infográficos}

1. Se sugiere seguir el modelo de escritura de ensayos elaborado a partir de Oshima y Hogue (1997), en el cual los pasos no son unidireccionales, sino que el alumno puede regresar de un paso a otro si es necesario (referirse a la Figura 1 presentada en la sección de resultados):

1. Planeación del infográfico: decidir qué tipo de contenido llevará, tipo de audiencia a la que se dirigirá, elementos visuales, secuencia lógica, software o programa de diseño que se utilizará, etc.

2. Elaborar el primer borrador.

3. Revisar el borrador.

4. Editar el borrador.

5. Publicar: entregar la versión final.

Este modelo para el diseño de los infográficos es similar al que presenta Alyahya (2019), el cual incluye los siguientes pasos: preparación, planeación, desarrollo, evaluación y publicación.

\section{Fase 4: Difusión de los infográficos}

1. Permitir a los alumnos difundir los infográficos entre la comunidad escolar en formato tanto impreso como digital, según sea el caso. Por ejemplo, los infográficos estáticos pueden difundirse en formato impreso en las instalaciones de la institución y por redes sociales o aplicaciones de mensajería instantánea. Los videoinfográficos, por su parte, pueden ser compartidos en plataformas de videos.

2. En la medida de lo posible, promover en los alumnos la difusión de los infográficos más allá de los límites escolares, de tal forma que lleguen a la comunidad profesional de la que formarán parte.

\section{BIBLIOGRAFÍA}


Alyahya, Dalia. "Infographics as a Learning Tool in Higher Education: The Design Process and Perception of an Instructional Designer". International Journal of Learning, Teaching and Educational Research, 18.1 (2019): 1-15. 15 de junio 2019. https://doi.org/10.26803/ijlter.18.1.1

Cassany, Daniel; Luna, Marta y Sanz, Glòria. Enseñar lengua. Barcelona: Graó, 2000.

Catalá, Glòria; Catalá, Mireia; Molina, Encarna y Monclús, Rosa. Evaluación de la comprensión lectora. Barcelona: Graó, 2001.

Davis, Mark y Quinn, David. "Visualizing text: The new literacy of infographics". Reading Today, 31 (2013): 16-18.

Damyanov, Ivo y Tsankov, Nikolay. "The Role of Infographics for the development of Skills for Cognitive Modeling in Education”. International Journal of Emerging Technologies in Learning, 13.1 (2018): 82-92. 20 de junio 2018. doi: 10.3991/ijet.v13i01.7541

De Pablos, José Manuel. "Siempre ha habido infografía". Revista Latina de Comunicación Social, 5 (1998): $1-5$

Guzmán, Yunuen; Lima, Natalia y Ferreira, Sirléia. "La experiencia de elaborar infografías didácticas sobre diversidad sexual”. Revista Latina de Comunicación Sexual, 70 (2015): 961 981. 20 de junio 2018. doi: 10.4185/RLCS-2015-1080

Minervini, Mariana Andrea. "La infografía como recurso didáctico". Revista Latina de Comunicación Social, 59.8 (2005). http://www.revistalatinacs.org/200506minervini.pdf

Oshima, Alice y Hogue, Ann. Introduction to Academic Writing Second Edition. New York: Longman, 1997.

Ponce, Andrea; Rangone, Claudia y Funes, Mónica. "Relato de experiencia: Diseño de infografías como estrategia de enseñanza en Educación para la Salud en Ciencias Naturales y su didáctica en profesorados para la educación primaria de la provincia de Córdoba”. VIII Jornadas Nacionales y $1^{\circ}$ Congreso Internacional sobre la Formación del Profesorado. Mar del Plata, Argentina, 2015.

Reinhart, Nancy. "Infografía Didáctica: producción interdisciplinaria de infografías didácticas para la diversidad cultural". Centro de Estudios en Diseño y Comunicación, (2010): 119-191. 
Sudakov, Ivan; Bellsky, Thomas; Usenyuk, Svetlana y Polyakova, Victoria. "Infographics and Mathematics: A Mechanism for Effective Learning in the Classroom”. PRIMUS, 26.2 (2016): 158-167, DOI: 10.1080/10511970.2015.1072607(2016)

Tapia, Alonso. Motivar para el aprendizaje: teoría y aprendizaje. España: EDEBÉ, 1997.

Tébar, Lorenzo. El perfil del profesor mediador. Madrid: Santillana, 2003.

\section{ANEXO}

\section{Rúbrica para valorar los infográficos producidos por los alumnos}

\begin{tabular}{|c|c|c|c|c|c|}
\hline Rubro & Aspecto & $\begin{array}{c}\text { Excelente ( } 4 \\
\text { puntos) }\end{array}$ & Bueno (3 puntos) & Regular (2 puntos) & Malo (1 punto) \\
\hline \multirow[t]{5}{*}{$\begin{array}{l}\text { 1. Característica } \\
\text { de contenido } \\
\text { del organizador } \\
\text { gráfico }\end{array}$} & $\begin{array}{l}1.1 \text { Apoyo } \\
\text { para la } \\
\text { comprensión } \\
\text { de texto }\end{array}$ & $\begin{array}{l}\text { Todas las imágenes y } \\
\text { textos presentados } \\
\text { permiten mejorar el } \\
\text { entendimiento de la } \\
\text { información. }\end{array}$ & $\begin{array}{l}\text { Algunas de las } \\
\text { imágenes y/o partes } \\
\text { del texto permiten } \\
\text { mejorar el } \\
\text { entendimiento de la } \\
\text { información. }\end{array}$ & $\begin{array}{l}\text { Pocas imágenes y/o } \\
\text { textos presentados } \\
\text { permiten el } \\
\text { entendimiento de la } \\
\text { información. }\end{array}$ & $\begin{array}{l}\text { Las imágenes y el } \\
\text { texto no tienen } \\
\text { concordancia, lo } \\
\text { cual provoca poca } \\
\text { comprensión } \\
\text { errónea de la } \\
\text { información. }\end{array}$ \\
\hline & $\begin{array}{l}\text { 1.2 Precisión } \\
\text { de la } \\
\text { información }\end{array}$ & $\begin{array}{l}\text { La infografía contiene } \\
\text { solamente elementos } \\
\text { textuales y visuales } \\
\text { concretos y esenciales } \\
\text { para la comprensión } \\
\text { del contenido. }\end{array}$ & $\begin{array}{l}\text { La infografía contiene } \\
\text { elementos textuales y } \\
\text { visuales que no son } \\
\text { esenciales pero que } \\
\text { permiten la } \\
\text { comprensión del } \\
\text { contenido. }\end{array}$ & $\begin{array}{l}\text { La infografía contiene } \\
\text { elementos textuales y } \\
\text { visuales que no son } \\
\text { esenciales y que } \\
\text { dificultan la } \\
\text { comprensión del } \\
\text { contenido. }\end{array}$ & $\begin{array}{l}\text { La infografía } \\
\text { contiene elementos } \\
\text { textuales y visuales } \\
\text { en abundancia, lo } \\
\text { cual dificulta la } \\
\text { comprensión del } \\
\text { contenido. }\end{array}$ \\
\hline & $\begin{array}{l}\text { 1.3 Logro del } \\
\text { objetivo del } \\
\text { organizador } \\
\text { gráfico }\end{array}$ & $\begin{array}{l}\text { Explica de manera } \\
\text { concisa las ideas } \\
\text { principales; explica de } \\
\text { manera concisa } \\
\text { conceptos clave. }\end{array}$ & $\begin{array}{l}\text { Explica de manera } \\
\text { concisa las ideas } \\
\text { principales; explica de } \\
\text { manera concisa algunos } \\
\text { conceptos clave. }\end{array}$ & $\begin{array}{l}\text { Explica ampliamente } \\
\text { las ideas principales } \\
\text { pero no explica de } \\
\text { manera concisa los } \\
\text { conceptos clave. }\end{array}$ & $\begin{array}{l}\text { Explica } \\
\text { ampliamente las } \\
\text { ideas principales; no } \\
\text { explica conceptos } \\
\text { clave. }\end{array}$ \\
\hline & 1.4 Referencia & $\begin{array}{l}\text { Todos los elementos } \\
\text { de la referencia } \\
\text { están en estilo APA } \\
\text { 6ta edición }\end{array}$ & $\begin{array}{l}\text { Faltan elementos en la } \\
\text { referencia del estilo } \\
\text { APA 6ta edición }\end{array}$ & $\begin{array}{l}\text { Proporciona referencia } \\
\text { pero no utiliza el } \\
\text { Estilo APA 6ta } \\
\text { edición }\end{array}$ & $\begin{array}{l}\text { No proporciona } \\
\text { referencia }\end{array}$ \\
\hline & $\begin{array}{l}1.5 \text { Redacción } \\
\text { y ortografía }\end{array}$ & $\begin{array}{l}\text { No hay faltas de } \\
\text { redacción ni de } \\
\text { ortografía }\end{array}$ & $\begin{array}{l}\text { Hay de } 1 \text { a } 3 \text { errores de } \\
\text { redacción y/o de } \\
\text { ortografía. }\end{array}$ & $\begin{array}{l}\text { Hay de } 4 \text { a } 6 \text { errores } \\
\text { de redacción y/o de } \\
\text { ortografía. }\end{array}$ & $\begin{array}{l}\text { Hay más de } 7 \\
\text { errores de redacción } \\
\text { y/o de ortografía. }\end{array}$ \\
\hline $\begin{array}{l}2 . \\
\text { Características } \\
\text { de forma del } \\
\text { organizador } \\
\text { gráfico }\end{array}$ & $\begin{array}{l}2.1 \\
\text { Coherencia } \\
\text { entre texto e } \\
\text { imagen }\end{array}$ & $\begin{array}{l}\text { Las imágenes y el } \\
\text { texto corresponden } \\
\text { entre sí en todo el } \\
\text { infográfico. }\end{array}$ & $\begin{array}{l}\text { Las imágenes y el texto } \\
\text { corresponden entre sí; } \\
\text { se visualiza falta de } \\
\text { coherencia texto- } \\
\text { imagen solamente en }\end{array}$ & $\begin{array}{l}\text { Las imágenes y el } \\
\text { texto corresponden } \\
\text { entre sí; se visualiza } \\
\text { falta de coherencia } \\
\text { texto-imagen } \\
\text { solamente en dos }\end{array}$ & $\begin{array}{l}\text { Las imágenes y el } \\
\text { texto corresponden } \\
\text { entre sí; se visualiza } \\
\text { falta de coherencia } \\
\text { texto-imagen en más }\end{array}$ \\
\hline
\end{tabular}




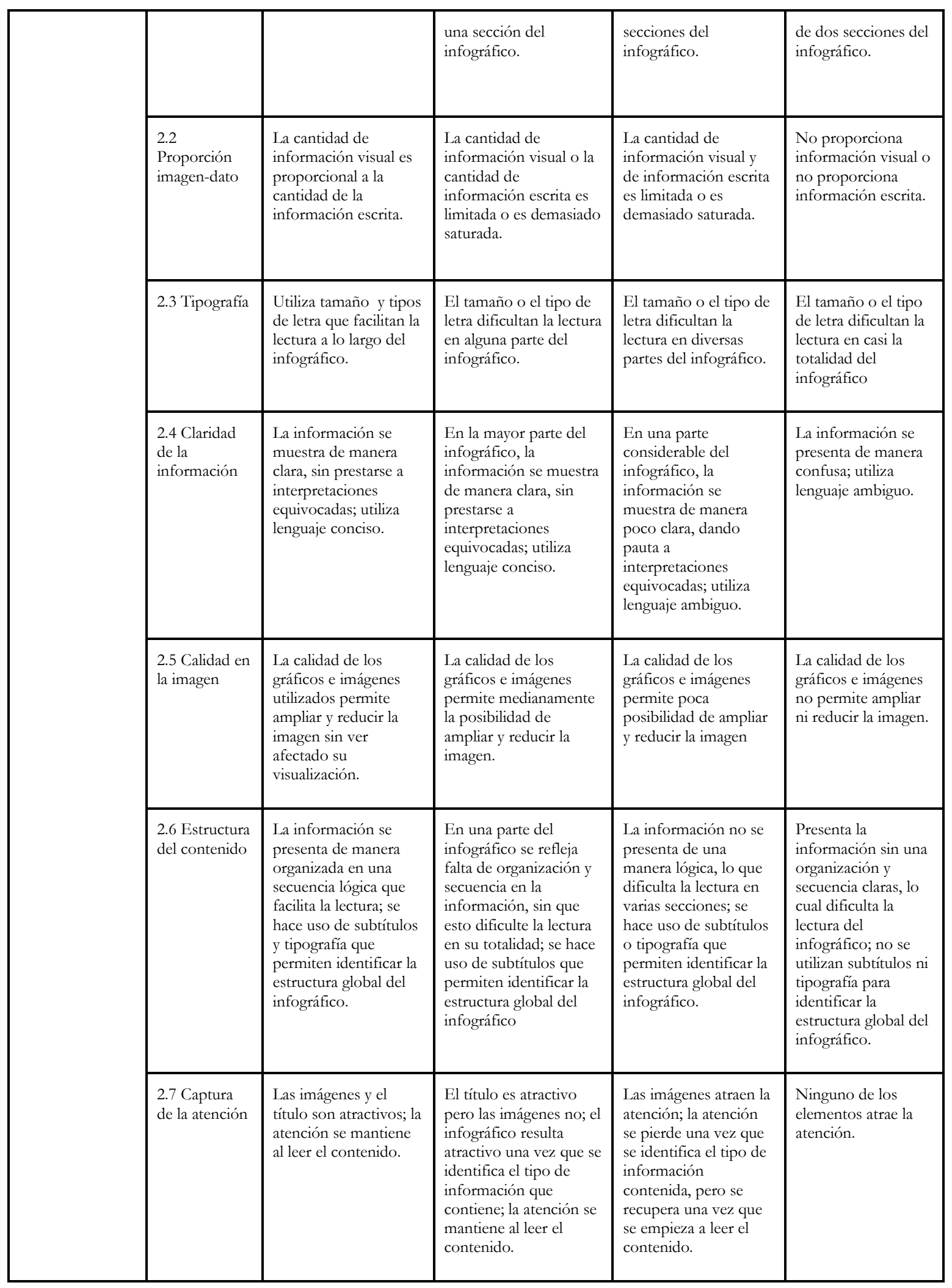

